$\xi=-1$

\title{
Using google location APIs to find an accurate criminal accident location
}

\author{
Muhammad Irwan Padli Nasution ${ }^{1}$, Samsudin Samsudin ${ }^{1}$ \\ ${ }^{1}$ Universitas Islam Negeri Sumatera Utara Medan Indonesia \\ *Corresponding author E-mail: irwannst@uinsu.ac.id
}

\begin{abstract}
Globalization has brought about a change in social behavior of society. The open access to information from the development and utilization of Information and Communication Technology has brought about a very significant change in the culture and behavior of society. Current-ly, Smartphone as a mobile-based communication tool has many benefits for use by the community. Various features contained in it so that an application can be developed for use by the public as a media reporting the location of the crime. Thus, the security forces will be assisted to obtain accurate information about the position where the crime occurred. One of the unique features of mobile applications is location awareness. To get an accurate location is necessary. Using Google Location APIs to get more accurate location. Applications like this do not exist in Indonesia, so it can be developed to help the police quickly get to the location of the case.
\end{abstract}

Keywords: Android; Criminal; Smartphone; Google API

\section{Introduction}

From print and electronic media currently often hear the occurrence of various criminal acts that cause people to feel afraid and uncomfortable. The social gap between rich and poor has caused problems in society. So no, wonder the crime rate increases due to the weight of life burden borne. Crime is anything that violates the law or an act of crime. Crimes have become a serious social problem for almost all of the world's public order, even more so nowadays more and more rampant crime cases occur where the perpetrators may be of all ages, children, young, adult can perform a variety of criminal acts.

Various preventions and protections to the community continue to be done by government. On the Police of the Republic of Indonesia has provided various phone contact numbers as call centers to receive various complaints from the public. The phone number is located in Police office state, so the public is recommended to the nearest of the location with its current position. This is needed so that the police can quickly move to the location of the case. However, the weakness of this manual system is that community must know exactly and correctly the phone contact number in the Police office state. This era so that smartphone more cheaper and easier to obtain. It is now a requirement of modern society today. Thus, this tool can be used to assist the public in complaining of criminal acts that occur around the environment where he was. It can be developed an Android Based Application. Applications will be useful for the community to be able to connect automatically with phone contact numbers in the nearest Police office state from their position of the criminal at that time. Applications like this do not exist in Indonesia, so it can be developed to help the police quickly get to the location of the case.

\section{Android based technology}

Currently the popularity of Android increasingly day. Many emerging vendors who sell their smartphones using the Android operating system. In addition, more and more people want to make the Android apps to be uploaded in Google Play Store. The android is an operating system for linux-based mobile devices that includes operating systems, middleware and applications. The android provides an open platform for developers to create their apps. Initially, Google Inc. buy Android Inc. which is a newcomer who makes software for smartphones and then develops Android formed Open Handset Alliance, a consortium of 34 hardware companies, software and telecommunications, including Google, HTC, Intel, Motorola, Qualcomm, T-Mobile, and Nvidia. The first mobile phone to use the Android operating system is the HTC dream, which was released on October 22, 2008. At the end of 2010 , it is estimated that almost all mobile vendors in the world use android as the operating system. Android's popularity continues to grow, not just from the number of devices that adopt this platform, but also telecom operators who are beginning to provide more focus on this Google-developed opensource platform. Software android as a complete platform, open, free and other information can be downloaded freely and completely by visiting the website: http://developer.android.com.

The android also continues to develop. The latest version of Android in 2018 is Oreo bringing big changes to the interface. In the development of this application required a smartphone that already has a GPS (Global Positioning System) feature. Now, all Android devices must be equipped with GPS features as it allows your smartphone to use navigation apps like Google Maps and also track your location for geo location features. Some GPS capabilities, among others, can provide information about position, speed, and time quickly, accurately, cheaply; anywhere on earth is not dependent on the weather. 


\section{Application development}

In the early stages, identification of existing problems and solutions to identified problems has been identified. After that initialization is done in the form of identification of stake holder system to be developed. Stake holder associated with the development of this system is community and end user support is the police. Once the stakeholders are known to be tracked to collect the information and data required for system development. The next step is analysis. At this stage analysis of criminal reporting process conducted by the community. At this stage there are several reporting processes that exist, among others, namely: (1).the public reports a criminal incident or incident to the police nearest to the call center service; (2). there are reports from the public that the police officially direct personnel to investigate to the scene of the accident; (3). Reports conducted by the community are processed by screening which is then followed up by the Criminal Investigation Agency of the Indonesian National Police; (4). The police handle reports based on cases occurring on the basis of the severity of a case to be sentenced in accordance with the criminal law. The next stage is design, at this stage designed the best application possible, for the application can be used easily (user friendly). The user interface is an aspect of a computer system or program that can be viewed, heard, or perceived by humans, and the commands or mechanisms that the user uses to control the operation and input of data on a computer. In Android application development developers usually use Android Studio as Integrated Development Environment (IDE).

In order for the system to run properly, we recommend using a smartphone with a minimum android version 8.0, and smartphone have GPS facility. Furthermore, if the application has been installed then, the public as the reporter directed to the registration menu to fill in the name and number of his ID. The goal is to avoid any false reports so that when the input of the ID card is given automatically will connect to the electronic ID card to match the identity of the community. After charging the reporting data, the application can then be used. As the Figure 1 below is the application interface display on the smartphone.

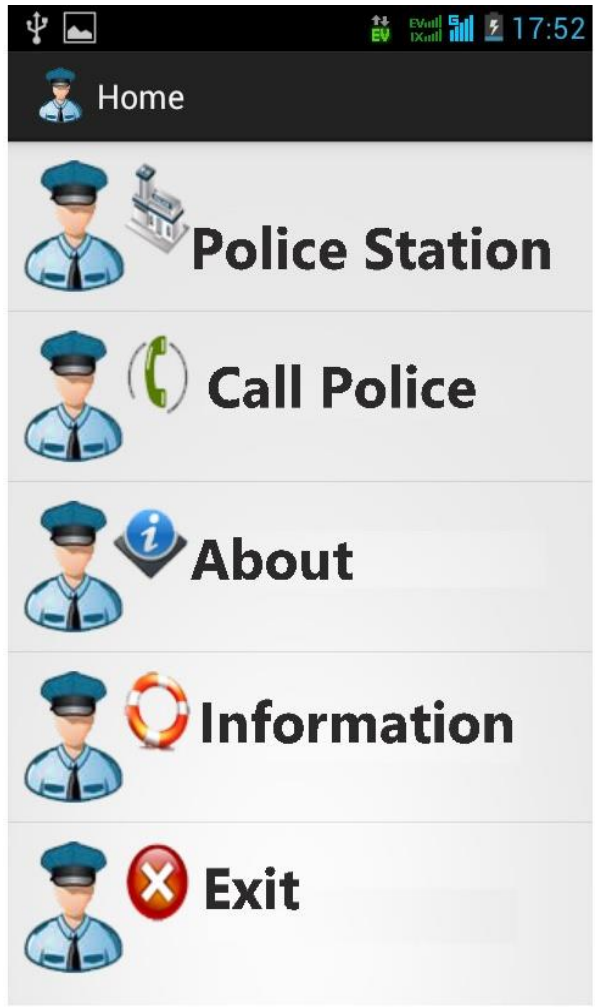

Fig. 1: Main Page Menu Display.

There are five menu items that can be used are: (1). Police Station; (2). Call Police; (3). About; (4). Information; (5). Exit. The Police
Station menu is used to link scene positions to call center police. The Call Police menu is used to talk with the nearest police to the location of the case. The About menu contains about the version of application used. Information menu contains about location of police station in an area. The exit menu is used to exit the application.

\section{The system working}

One of the unique features of mobile applications is location awareness. Mobile users take their devices with them everywhere, and adding location awareness to your app offers users a more contextual experience. The location APIs available in Google Play services facilitate adding location awareness to your app with automated location tracking, geofencing, and activity recognition. Specifically, use the fused location provider to retrieve the device's last known location. The fused location provider is one of the location APIs in Google Play services. It manages the underlying location technology and provides a simple API so that you can specify requirements at a high level, like high accuracy or low power. It also optimizes the device's use of battery power. Use of the app is very easy. If you want to report the crime scene then run the application and then simply press the "Police Station" as shown in Figure 1. When selecting the Police Station menu, the application will work so it can know the current location of the user is CP (Current Position), and the location of the nearest Police Station from the Police Station in Medan City. CP is the position of the location where the user is present when this app is used. $\mathrm{CP}$ position can vary and vary according to location where the user's whereabouts are located in which area. When to get the $\mathrm{CP}$ position, the position must be outdoors so that the smartphone used can connect to GPS to take the position of its location point. GPS data is then imported from Google maps. To help Google Maps find your location with the most accurate blue dot, use highaccuracy mode. In the previous application was recorded all the location position of the 12 existing Police Station in Medan City and has been introduced on coding program by taking data latitude and that can from Google maps[3] according to the of the address of $12 \mathrm{in}$. Then the CP point compared to all locations in the 12 points of Police Station in Medan City. The smallest distance difference is the closest location from the point of $\mathrm{CP}$ to the nearest Police Station, and then the public which wants to report immediately can make a call automatically to the nearest Police Station that is the position of P-4 Police Station. The work process of the above explanation can be seen on the Figure 2 below,

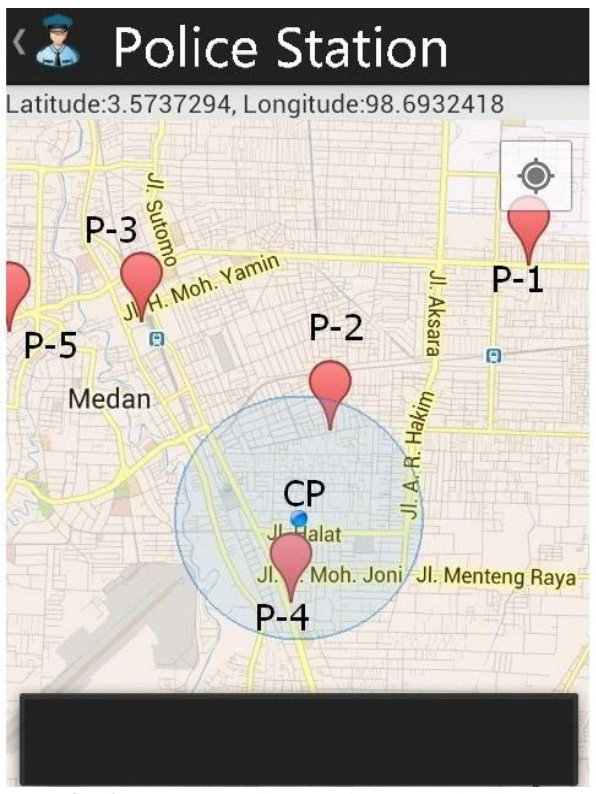

Fig. 2: Nearest Police Station Search View. 


\section{Conclusion}

The development of Information and Communication Technology has brought many benefits to human life. The development of criminal call center apps requires android-based smartphone devices that are relatively inexpensive and easily obtainable on the free market. Because the open source then, a lot of people who develop applications for Android. This application can be used for all people from adolescence to adulthood. The call center application of this criminal act can be used by the public to report criminal events or acts. The location position of the GPS has received the police, so it will make it faster and easier to get the scene. The location and context APIs harness the sensors and signals of mobile devices to provide awareness of user actions and their environment, enabling delightful and engaging experiences that simplify user interactions, provide assistance, and help users to better understand themselves.

\section{References}

[1] Wisnuh, E.W, (2012), Asiknya Bernavigasi dengan Ponsel GPS, Andi, Yogyakarta.

[2] https://developer.android.com/studio/, last visit: 31.05.2018

[3] https://support.google.com/maps/?visit_id=0$636635540928496488-747468582 \&$ rd=4\#topic $=3092425$, last visit: 31.05 .2018 .

[4] Nasution, Muhammad Irwan Padli, (2008), Urgensi Keamanan Pada Sistem Informasi, Journal Iqra' Volume 02 Nomor 02.

[5] M.I.P. Nasution, S. Dewi Andriana, P. Diana Syafitri, E. Rahayu and M.R.Lubis, "Mobile device interfaces illiterate" Technology, Informatics, Management, Engineering \&Environment (TIME-E), 2015 International Conference on, Samosir, 2015, pp. 117-120, doi $=\{10.1109 /$ TIME-E.2015.7389758 $\}$.

[6] https://developers.google.com/maps/documentation/geolocation/intr o, last visit: 12.06.2018. 